\title{
Diabetic ketoacidosis in pregnancy
}

\author{
Rosália S. Coutada ${ }^{1 *}$, Soraia S. Cunha ${ }^{1}$, Elisabete S. Gonçalves ${ }^{2}$, Ana P. Gama ${ }^{1}$, \\ João P. Silva ${ }^{1}$, Paula M. Pinheiro ${ }^{1}$
}

\begin{abstract}
${ }^{1}$ Department of Obstetrics and Gynecology, Unidade Local de Saúde do Alto Minho, Viana do Castelo, Portugal ${ }^{2}$ Department of Obstetrics and Gynecology, Centro Hospitalar Universitário do Algarve, Faro, Portugal
\end{abstract}

Received: 30 March 2018

Accepted: 23 May 2018

\section{*Correspondence:}

Dr. Rosalia S. Coutada,

E-mail: rosaliacoutada@gmail.com

Copyright: (C) the author(s), publisher and licensee Medip Academy. This is an open-access article distributed under the terms of the Creative Commons Attribution Non-Commercial License, which permits unrestricted non-commercial use, distribution, and reproduction in any medium, provided the original work is properly cited.

\begin{abstract}
Diabetic ketoacidosis in pregnancy is a rare but potential life-threatening condition for the mother and the fetus. It tends to occur latter in pregnancy and is more common in patients with pregestational diabetes. Obstetricians should be aware of the events that can trigger diabetic ketoacidosis in pregnancy. Prompt recognition and aggressive treatment of this condition are essential in order to reduce perinatal mortality and morbidity. The authors present a case of a pregnant woman with type 1 diabetes with a poor surveillance of pregnancy and noncompliance to treatment that develops severe diabetic ketoacidosis at 34 weeks of gestation.
\end{abstract}

Keywords: Diabetic ketoacidosis, Pregnancy, Type 1 diabetes

\section{INTRODUCTION}

Diabetic ketoacidosis (DKA) is a serious acute complication of diabetes and it is characterized by uncontrolled hyperglycemia, metabolic acidosis and ketosis. ${ }^{1}$ The occurrence of DKA during pregnancy is rare, with an estimated incidence of $1-3 \%$ of all diabetic gestations. ${ }^{2,3}$ Although more common in patients with type 1 diabetes, it may affect women with type 2 diabetes or, more rarely, gestational diabetes. ${ }^{4}$ Physiological adaptations related to pregnancy put the diabetic gravid at increased risk of DKA episodes. Pregnancy is a state of insulin resistance, created by hormones with counterregulatory actions (prolactin, human placental lactogen, progesterone and cortisol). Moreover, in pregnancy there is an accelerated starvation since glucose is readily absorbed by the placenta and the fetus, increasing lipolysis and tendency toward ketones formation. The acid-base state of pregnancy is compensated respiratory alkalosis, which results in decreased buffering capacity. ${ }^{1,3}$ DKA is a state of inadequate insulin action that is perceived as hypoglycemia at the level of target cells (adipocytes, liver and muscle). In consequence, there is a reduction in glucose utilization in peripheral tissues and an increase in gluconeogenesis, glycogenolysis and lipolysis, which contribute to hyperglycemia and ketogenesis. The osmotic diuresis leads to hypovolemia, and electrolytes abnormalities are the result of dehydration and acidotic state. ${ }^{1,5}$ Maternal DKA produces fetal distress through various mechanisms. Fetal hypoxia results from decreased placental perfusion as a consequence of maternal hypovolemia and acidemia. The direct transfer of ketoacids and glucose across the placenta leads to fetal acidosis and hyperinsulinemia, which increases the demand for oxygen. In addition, fetal hypokalemia can place the fetus at risk for serious cardiac arrhythmias, and maternal hypophosphatemia leads to decreased oxygen supply to the fetus. ${ }^{5,6}$ DKA occurs later in pregnancy, usually in second or third trimesters. It is necessary a great level of suspicion to diagnose this condition, once it usually occurs at lower blood glucose levels and it progresses more rapidly than in nonpregnant patients. Despite this, its occurrence may represent a life-threatening event for both the mother and 
her fetus. ${ }^{1,7}$ The purpose of this article is to describe a case report of DKA in pregnancy and review the literature on this relatively uncommon condition.

\section{CASE REPORT}

A 36-years-old woman, gravida 5, para 4, with type 1 diabetes for 12 years, was brought to the emergency department at $34+3$ weeks of gestation by prostration, vomiting, poor oral intake and diffuse abdominal pain, with two days of evolution. Despite the low attendance at diabetes controls, there weren't records of end organ dysfunction. This pregnancy was non-planned, and she didn't perform a preconception consultation. During the current pregnancy, she missed the majority of appointments with a multidisciplinary team of Pregnancy and Diabetes, and she had an inadequate metabolic control evaluated by glycated hemoglobin $(11.5 \%, 8.1 \%$ and $9.6 \%$, in first, second and third trimesters, respectively). On admission, she was confused, not oriented in time or space, answering to simple questions and denying administration of insulin for several days. Her vital signs were blood pressure of 113/68 $\mathrm{mmHg}$, heart rate of 112 beats/minute, respiratory rate of 40 cycles/minute and axillary temperature of $36{ }^{\circ} \mathrm{C}$. On physical examination she was prostrated, dehydrated and had ketonic breath. Pelvic examination revealed a cervix $30 \%$ effaced, softened and $3 \mathrm{~cm}$ dilated. Obstetric ultrasound showed a fetus with vitality, in cephalic presentation, normal amniotic fluid and umbilical artery Doppler, and cardiotocography presented episodes of bradycardia. Maternal analytics revealed a severe DKA (Table 1).

\section{Table 1: Laboratory results at diagnosis of DKA.}

\begin{tabular}{|ll|}
\hline Biochemical parameter & \\
\hline Glucose $(\mathrm{mg} / \mathrm{dl})$ & 191 \\
\hline Arterial $\mathrm{pH}$ & 7,04 \\
\hline Bicarbonate $(\mathrm{mEq} / \mathrm{l})$ & $<3$ \\
\hline Sodium $(\mathrm{mEq} / \mathrm{l})$ & 136 \\
\hline Potassium $(\mathrm{mEq} / \mathrm{l})$ & 4,8 \\
\hline Anion gap $(\mathrm{mEq} / \mathrm{l})$ & 18 \\
\hline Serum and urine ketones & Positives \\
\hline Creatinine $(\mathrm{mg} / \mathrm{dl})$ & 0,77 \\
\hline
\end{tabular}

She was managed by a multidisciplinary team (Obstetrician, Intensivist, Anesthesiologist and Neonatologist) and immediate treatment was started with intravenous fluids, insulin infusion and bicarbonate. After initial stabilization, and according with gestational age, the critical state of the pregnant and absence of fetal cardiotocography improvement, a cesarean section was performed. The female newborn weighed $2875 \mathrm{~g}$, had an Apgar score of 6/8/9, an arterial $\mathrm{pH}$ in blood cord of 6.8 with a base deficit of $14 \mathrm{mmol} / \mathrm{l}$ and was admitted to neonatal intensive care unit (NICU). The mother was discharged from intensive care unit two days after the cesarean and had a puerperium without other intercurrences; at this time, she had reassumed regular vigilance of diabetes. The newborn was discharged from NICU in day seven of life and at eighteen months of life had a normal psychomotor development.

\section{DISCUSSION}

The incidence of maternal and fetal mortality related with DKA is presumed to be decreasing in recent years with the improvement in diabetes and pregnancy care. ${ }^{5,8}$ Maternal mortality secondary to DKA is around 5-15\% and fetal death rates of $9-36 \%$ were reported. ${ }^{1,6,7,9}$ The long-term outcomes of fetuses exposed in utero to episodes of maternal DKA are not well defined, but some studies suggest an association between the level of ketoacidosis and worse neurodevelopmental outcomes. ${ }^{2,9,10}$ Pregnancy is a state of insulin resistance, accelerated starvation and decreased buffering capacity (compensated respiratory alkalosis of pregnancy). These physiological adaptations related to gestation put the diabetic gravid at increased risk of DKA episodes. ${ }^{3,9}$ In this case report, the precipitating factor of the DKA was noncompliance to the treatment. Others well described factors are acute illness or infection, unrecognized new onset diabetes, insulin pump failure, dehydration, stress of labor, emesis and gastroparesis. Some medications used in obstetrics, like steroids and betamimetics can worsen insulin resistance and hyperglycemia. ${ }^{7,11}$ The clinical and laboratory manifestations of the DKA in pregnancy are similar to that of non-pregnant patients but the progression is faster, and it could occur at lower blood glucose levels often causing a delay in diagnosis (Table 2). ${ }^{7,9}$ In the present case report, glucose blood levels were slightly elevated, and levels of bicarbonate were extremely low.

Table 2: Clinical and laboratory manifestations of DKA.

$\begin{array}{ll}\text { Signs and symptoms } & \text { Laboratory features } \\ \text { Malaise } & \text { Hyperglycemia }(>300 \mathrm{mg} / \mathrm{dl}) \\ \text { Nausea } & \text { Acidosis }(\mathrm{pH}<7.3) \\ \text { Vomiting } & \text { Low bicarbonate }(<15 \mathrm{mEq} / \mathrm{l}) \\ \text { Abdominal pain } & \text { Elevated anion gap }(>12 \\ \text { Polyuria } & \text { mEq/l) } \\ \text { Polydipsia } & \text { Serum and urine ketones } \\ \text { Weakness } & \text { positives } \\ \text { Tachycardia } & \text { Renal dysfunction } \\ \text { Hyperventilation } & \text { Serum levels of potassium } \\ \text { Hypotension } & \text { often normal (but total body } \\ \text { Ketonic breath } & \text { potassium is decreased) } \\ \text { Dehydration } & \\ \text { Altered } & \\ \text { consciousness/coma } & \end{array}$

DKA is a medical and obstetric emergency requiring immediate management by a multidisciplinary team. ${ }^{5}$ If not corrected, DKA can progress to a state of inadequate tissue perfusion, diminished cardiac and renal function, multiorgan failure, and even death. ${ }^{11}$ Principles of treatment are the same that for non-pregnant patients and include volume replacement, insulin therapy, correction 
of acidosis and abnormalities of electrolytes, search and treatment of precipitating factor (Table 3). ${ }^{5,6}$ Bicarbonate administration during DKA event is a matter of debate in the literature..$^{2,5,9}$ In this case report, given the severity of acidemia ( $\mathrm{pH} \quad 7.04$ and bicarbonate $<3 \quad \mathrm{mEq} / \mathrm{l}$ ) replacement of bicarbonate was performed.

Table 3: Management of DKA in pregnancy.

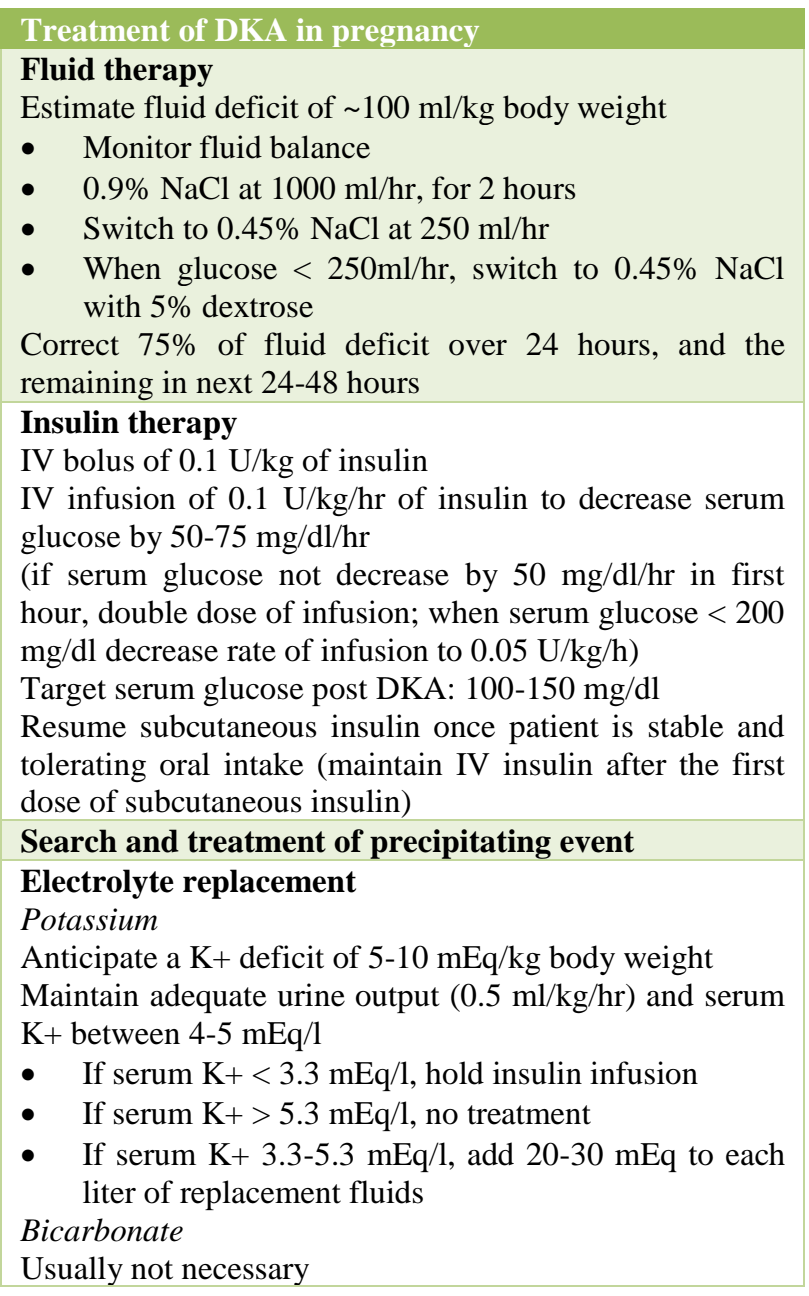

In the obstetric point of view, the cardiotocography reveals decreased or absent variability, absent accelerations, or late decelerations. The other features of fetal biophysical profile may also be abnormal and Doppler studies could show transient signs of redistribution. ${ }^{1}$ Some of the fetal effects of DKA may only be transient and reverse after treatment of the mother. ${ }^{9}$ Timing of delivery must be individualized based on gestational age, maternal and fetal responses to therapy. Emergency cesarean before maternal stabilization should be avoided because it could further aggravate the maternal condition. Delivery for fetal indications should be reserved for fetal impairment that persists after maternal resuscitation. ${ }^{5,6}$ The decision of cesarean delivery in this case report was based in gestational age, severity of maternal DKA and absence of fetal response after initial measures for mother stabilization. Prevention of DKA is essential; all diabetic women planning a pregnancy or already pregnant should be educated about the importance of compliance with therapy and early signs of DKA. On the other side, obstetricians should be aware of precipitants events that can trigger DKA in pregnancy. The prompt recognition and aggressive treatment of this infrequent but serious complication are essential in order to reduce maternal and perinatal mortality.

\section{Funding: No funding sources \\ Conflict of interest: None declared \\ Ethical approval: Not required}

\section{REFERENCES}

1. Sibai B, Viteri O. Diabetic ketoacidosis in pregnancy. Obstet Gynecol. 2014;123(1):167-78.

2. Veciana M. Diabetes ketoacidosis in pregnancy. Sem Perinatol. 2013;37:267-73.

3. American College of Obstetricians and Gynecologists. ACOG practice bulletin No. 60: Pregestational diabetes. Obstet Gynecol. 2005;105: 675-85.

4. Hawthorne G. Maternal complications in diabetic pregnancy. Best Pract Research Clinic Obstet Gynaecol. 2011;25:77-90.

5. Carroll M, Yeomans E. Diabetic ketoacidosis in pregnancy. Crit Care Med. 2005;33:347-53.

6. Pinto M, Villena J. Diabetic ketoacidosis during gestational diabetes. A case report. Diabetes Res Clin Pract. 2011;93:92-4.

7. Kamalakannan D, Baskar V, Barton D, Abdu T. Diabetic ketoacidosis in pregnancy. Postgrad Med J. 2003;79:454-7.

8. Schneider M, Umpierrez G, Ramsey R, Mabie W, Bennett K. Pregnancy complicated by diabetic ketoacidosis: maternal and fetal outcomes. Diabetes Care. 2003;26:958-9.

9. Parker J, Conway D. Diabetic ketoacidosis in pregnancy. Obstet Gynecol Clin N Am. 2007;34:53343.

10. Stenerson M, Collura C, Rose C, Lteif A, Carey W. Bilateral Basal Ganglia Infarctions in a Neonate Born During Maternal Diabetic Ketoacidosis. Pediatrics. 2011;128:707-10.

11. Chico M, Levine S, Lewis D. Normoglycemic diabetic ketoacidosis in pregnancy. J Perinatol. 2008;28:310-2.

Cite this article as: Coutada RS, Cunha SS, Goncalves ES, Gama AP, Silva JP, Pinheiro PM. Diabetic ketoacidosis in pregnancy. Int $\mathrm{J}$ Reprod Contracept Obstet Gynecol 2018;7:2945-7. 